\title{
Effect of shoulder features during friction spot extrusion welding of 2024-T3 to 6061-T6 aluminium alloys
}

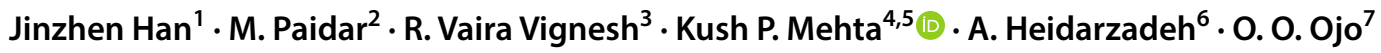

Received: 21 April 2020 / Revised: 4 June 2020 / Accepted: 22 June 2020 / Published online: 4 July 2020

(c) The Author(s) 2020

\begin{abstract}
Friction spot extrusion welding process is successfully performed on dissimilar aluminum alloys of AA2024-T3 and AA6061T6 under the influence of shoulder features. The joints were analysed by microstructural features and mechanical properties using conventional and advanced tools of visual inspection, optical microscopy, scanning electron microscopy, transmission electron microscopy, electron back scattered diffractions, tensile testing and hardness testing. The results revealed that the joining was obtained by combination of mechanical locking from extruded material of top surface to predrilled bottom surface and diffusion in solid state. The stir zone and plastically deformed metal flow zone were influenced by scroll shoulder and smooth shoulder features. The tensile specimen of scroll shoulder was resulted to higher fracture load of $6381 \mathrm{~N}$ whereas the same was $4916 \mathrm{~N}$ in case of smooth shoulder. The interface of between plastically deformed metal flow zone and base material of AA6061-T6 can be considered as critical/weakest zone in case of friction spot extrusion. The variations of hardness were observed in stir zone, plastically deformed metal flow zone and thermo-mechanically affected zone in case of friction spot extrusion welding process.
\end{abstract}

Keywords Dissimilar joints $\cdot$ Friction spot extrusion $\cdot$ Friction stir $\cdot$ Mechanical properties $\cdot$ Microstructure $\cdot$ Probeless tool · Welding

Jinzhen Han

hanjinzihen@yeah.net

$\triangle$ Kush P. Mehta

kush.mehta@aalto.fi; Kush_2312@yahoo.com

1 Zhejiang Industry Polytechnic College, Shaoxing 312000, Zhejiang, China

2 Department of Material Engineering, South Tehran Branch, Islamic Azad University, 1459853849 Tehran, Iran

3 Department of Mechanical Engineering, Amrita School of Engineering, Amrita Vishwa Vidyapeetham, Coimbatore, India

$4 \quad$ Advanced Manufacturing and Materials Research Group, Department of Mechanical Engineering, School of Engineering, Aalto University, Espoo, Finland

5 Department of Mechanical Engineering, School of Technology, Pandit Deendayal Petroleum University, Gandhinagar, Gujarat, India

6 Department of Materials Engineering, Azarbaijan Shahid Madani University, Tabriz, Iran

7 Department of Industrial and Production Engineering, Federal University of Technology Akure, Akure, Nigeria

\section{Introduction}

The demand of dissimilar aluminum (Al) welds is extensively increasing to meet the requirements of cost reduction, light weight structures and enhanced working efficiency of transport industries. Ojo et al. [1] mentioned that the spot lap welds of transport industries are conventionally produced by resistance spot welding, which are then advanced by frictionbased spot welding processes in recent time. Friction-based welding processes such as friction stir spot welding (FSSW), friction stir clinching (FSC), friction riveting, friction bit joining, friction flow drilling, friction forming and dieless friction stir extrusion joining are developed to produce different components with spot joining, as reported by some researchers [2, 3]. FSSW and friction stir clinching are found promising over resistance spot welding with large number of published articles as reported by Lin et al. [4] and also Uematsu and et al. [5]. However, the formation of exithole/ keyhole is one of the big issues in these processes, which is a spot of stress concentration under loading conditions as mentioned by Mehta and Patel [6]. Therefore, most recent developments are investigated keeping focus on repairing/ 
refilling/eliminating this inevitable exithole. Huang et al. [7] repaired exithole using consumable bit insertion as a secondary step after friction stir welding process. Behmand et al. [8] also suggested similar method of consumable tool application in exithole location to perform repairing during secondary phase. Reimann et al. [9] developed in built sleeve-clamping ring mechanism to refill the exithole at the time of retraction phase. They claimed improved mechanical properties after heat treatment procedure. Chen et al. [10] repaired the exithole using circular path movement of another probe tool around the exithole. However, new exithole was generated with that probe consisted tool which was comparatively smaller than original exithole. Shen et al. [11] welded dissimilar $\mathrm{Al}$ alloys using filling FSSW, wherein the exithole is refilled during manufacturing operation along with sound intermixing of materials. Bakavos et al. [12] performed FSSW on thin sheets of $\mathrm{Al}$ with probeless tools with different shoulder surface features. They mentioned that avoiding exithole formation in addition to undesirable hooking effect can be effectively performed using probeless tools. They also found that material flow patterns are greatly influenced by shoulder features that in turn useful in improving mechanical properties of joints. Paidar et al. [13-16] developed modified FSC that eliminates exithole by protuberance leveling in second stage using probeless tool. They subjected prob-less tool from the revert side on spot of clinching that in turn lead protuberance of material in the cavity of exit-hole along with similar leveling of base material. Mehta et al. [17] repaired exit-hole of dissimilar $\mathrm{Al}-\mathrm{Mg}$ friction stir welds with enhanced material mixing using probeless tool. They applied higher diameter prob-less tools in two different post welding stages at the exithole location with two subsequent progressive plunge depths to fill the cavity of exithole. In these processes, the either exithole is repaired or filled using consumable bit or utilizing surrounding material of exithole subjected in cavity by extrusion and/or forging action. However, these processes require secondary phase to eliminate exithole.

Using aforementioned concept of forging and extrusion by external non consumable tool, different welding processes are evolved, wherein the exithole is eliminated and joining is simultaneously obtained without increasing steps of manufacturing. Lazarevic et al. [18] spot joined $\mathrm{Al}$ and steel using non consumable tool keeping cavity in anvil and named as friction stir forming. The Al material is kept on steel material to send $\mathrm{Al}$ in the gap of steel and anvil cavity using plastic deformation caused by non-consumable tool. Evans et al. [19] developed process of lap welding named as friction stir extrusion, to obtain joining along the length of tool travel in the direction of workpiece, wherein the probeshoulder featured tool is inserted in Al workpiece while steel based workpiece is kept under that $\mathrm{Al}$ workpiece with specially fabricated grove designs. The $\mathrm{Al}$ is extruded in the specially fabricated grove of steel workpiece and that in turn lead to joining of $\mathrm{Al}$ and steel. Hussein et al. [20] named friction spot forming technique to produce $\mathrm{Al}$-steel welding using extrusion of $\mathrm{Al}$ in the grove of steel when $\mathrm{Al}$ is kept on steel, wherein maximum joint efficiency of $125 \%$ is claimed. Jarrell et al. [21] applied friction stir extrusion on thin sheets to obtain large length welds of Al-steel, without surface penetration caused by tool on Al side. Saju et al. [22] named dieless friction stir extrusion technique applied to join different $\mathrm{Al}$ alloys, wherein mechanical interlocking and metallurgical bonding is obtained used extruded material from top workpiece to bottom workpiece that is predrilled. They investigated effect of shoulder diameter on joining of Al alloys of 5052-H32 and 6061-T6. Saju and Narayanan [23] investigated effect of predrilled diameter on joint formation as a progress of dieless friction stir extrusion technique. They also claimed that investigated technique is better in terms of joint properties than conventional friction stir forming, FSSW and probeless FSSW. Saju and Narayanan [3] further investigated dieless friction stir extrusion with controlled plunge depth.

Considering promising results in initial studies, welding by extrusion concept is worth to expand with different variants and process parameters. Limited studies are available for $\mathrm{Al}-\mathrm{Al}$ welding using extrusion process. The research gap in effect of tool profile features on material flow behavior and subsequent influence on joint formation in case of friction extrusion processes is motivation. On account of this research gap, it makes sense to conduct the investigation on material flow, microstructure and joint properties influence under the effect of shoulder surface features for friction spot extrusion welding process. In the present investigation, scroll shoulder and smooth shoulder profiles are investigated for friction spot extrusion welding of dissimilar $\mathrm{Al}$ alloys between AA2024-T3 and AA6061-T6 to analyze mixing

Table 1 Mechanical properties of AA2024-T3 and AA6061-T6

\begin{tabular}{llll}
\hline Elongation (\%) & $\begin{array}{l}\text { Yield strength } \\
{[\mathrm{MPa}]}\end{array}$ & $\begin{array}{l}\text { Ultimate tensile } \\
{[\mathrm{MPa}]}\end{array}$ & Alloy \\
\hline 14 & 317 & 448 & AA2024-T3 \\
11 & 259 & 287 & AA6061-T6 \\
\hline
\end{tabular}


Table 2 Chemical compositions of AA2024-T3 and AA6061-T6 (wt $\%)$

\begin{tabular}{lllllll}
\hline $\mathrm{Cr}$ & $\mathrm{Mn}$ & $\mathrm{Mg}$ & $\mathrm{Si}$ & $\mathrm{Cu}$ & $\mathrm{Al}$ & Alloy \\
\hline 0.012 & 0.629 & 1.28 & 0.43 & 4.9 & Base & AA2024-T3 \\
0.104 & 0.056 & 0.87 & 0.61 & 0.21 & Base & AA6061-T6 \\
\hline
\end{tabular}

features, microstructural analysis and mechanical properties of joints.

\section{Experimental procedure}

$\mathrm{Al}$ alloys of AA2024-T3 (1.6 mm thickness) and AA6061T6 (1 mm thickness) were used in the present investigation. Tables 1 and 2 show mechanical properties and chemical compositions of the base materials used in this investigation, respectively.
The thickness of the base material is one of the crucial parameters in case of friction spot extrusion welding since extrusion material from top workpiece material extrudes into cavity of bottom workpiece with its volume limitation. Therefore, the workpiece kept on top side must be of higher thickness than the bottom side workpiece. In the present investigation, workpiece material of AA2024-T3 with higher thickness was kept on AA6061-T6 having lower thickness as shown in Fig. 1a. The bottom workpiece material (i.e. AA6061-T6) was predrilled with diameter of $3 \mathrm{~mm}$, in order to provide path of extrusion. The predrilled diameter is critical and selected based on previous study of Saju et al. [23].
Fig. 1 a Schematic of the process principle, and tool features b smooth shoulder, c scrolled shoulder
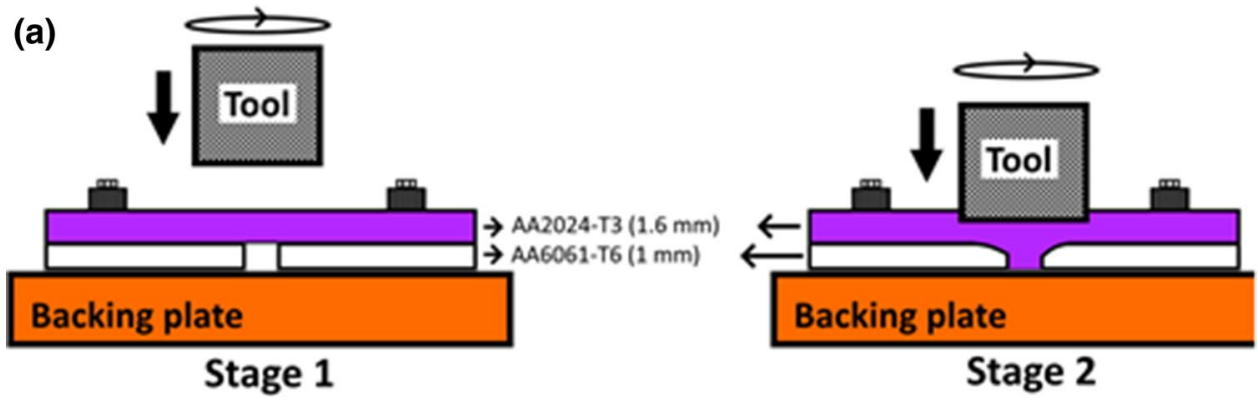

(b)

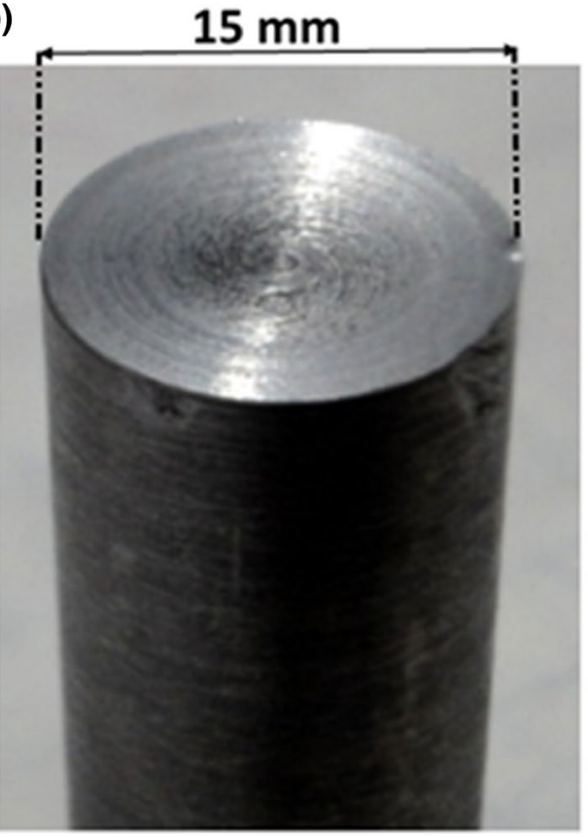

(c)

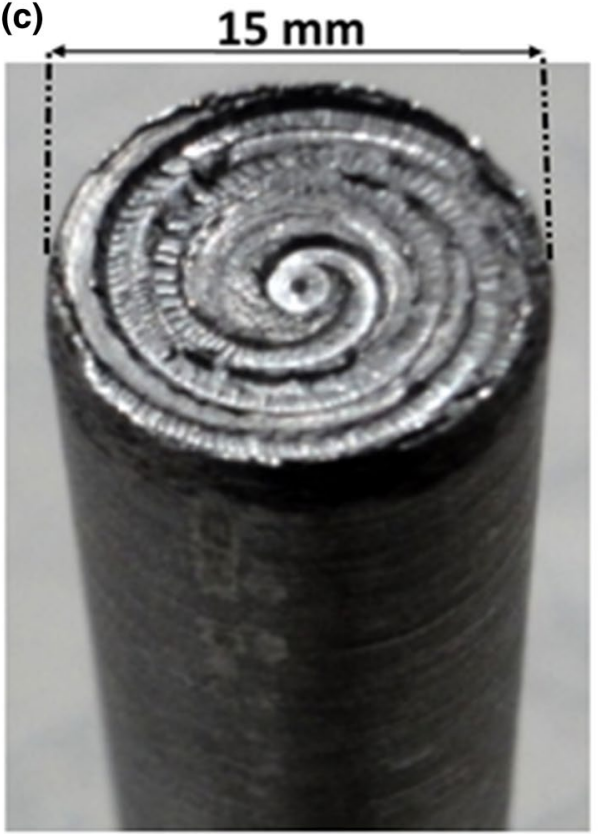


Two different probeless tools consist of $\mathrm{H} 13$ tool steel material with $15 \mathrm{~mm}$ shoulder diameter with different surface feature profiles of smooth (Fig. 1b) and scroll (Fig. 1c) were used in the present investigation. The process of friction spot extrusion welding was accomplished on CNC milling machine (FP4MK) with two stages. In first stage, the tool was rotated at $710 \mathrm{rpm}$ and plunge phase was initiated with tool plunge rate of $0.2 \mathrm{~mm} / \mathrm{min}$. As soon as the shoulder contacts workpiece surface, the tool was kept on the surface for $6 \mathrm{~s}$ and then further plunged to a depth of $0.4 \mathrm{~mm}$. The material that is kept on top surface (i.e. AA2024-T3) gets soften due to friction between tool and workpiece. This soften material extrudes downward in the cavity of bottom material (i.e. AA6061-T6) and subsequently cause joint formation. There were two different conditions with shoulder surfaces of smooth and scroll applied keeping rest other parameters constant as mentioned above. For each tool and subsequent processing conditions, five samples were prepared. Three samples for Tensile/Shear testing and two samples for macro and microstructural analysis.

After the experimental processing, the welded samples were analyzed with different analysis tools such as visual examination of surface crown appearance, cross sectional macro image, microstructural observations, electron backscattered diffraction (EBSD) patterns, tensile testing and hardness measurements. Barker reagent was used with electro-etching as a part of metallography procedure after performing standard grinding and polishing procedure, in order to develop samples for optical microscopy, scanning electron microscopy (SEM), transmission electron microscopy (TEM) and EBSD. The tensile testing was conducted to check the strength of the welds using Intron 5500R machine at a cross head speed of $2 \mathrm{~mm} / \mathrm{min}$. Tensile testing procedure and specimen dimensions used for testing are shown in Fig. 2. After tensile testing, the fractured surface of specimen was analyzed by SEM tool. The hardness measurements were also performed on a cross section of weld using indentation load of $100 \mathrm{~g}$ and $15 \mathrm{~s}$ holding time at $1 \mathrm{~mm}$ space between each indentation. The profile of hardness was analyzed by variations in two different lines from the center of both the workpieces (Fig. 3).

\section{Results and discussion}

\subsection{Surface crown appearance and macrographs}

Visual inspection of welded surfaces can be analyzed from Fig. 4 to understand the surface crown appearance from top and bottom surfaces of processed regions. The welded surfaces were observed defect free with minor flash formation
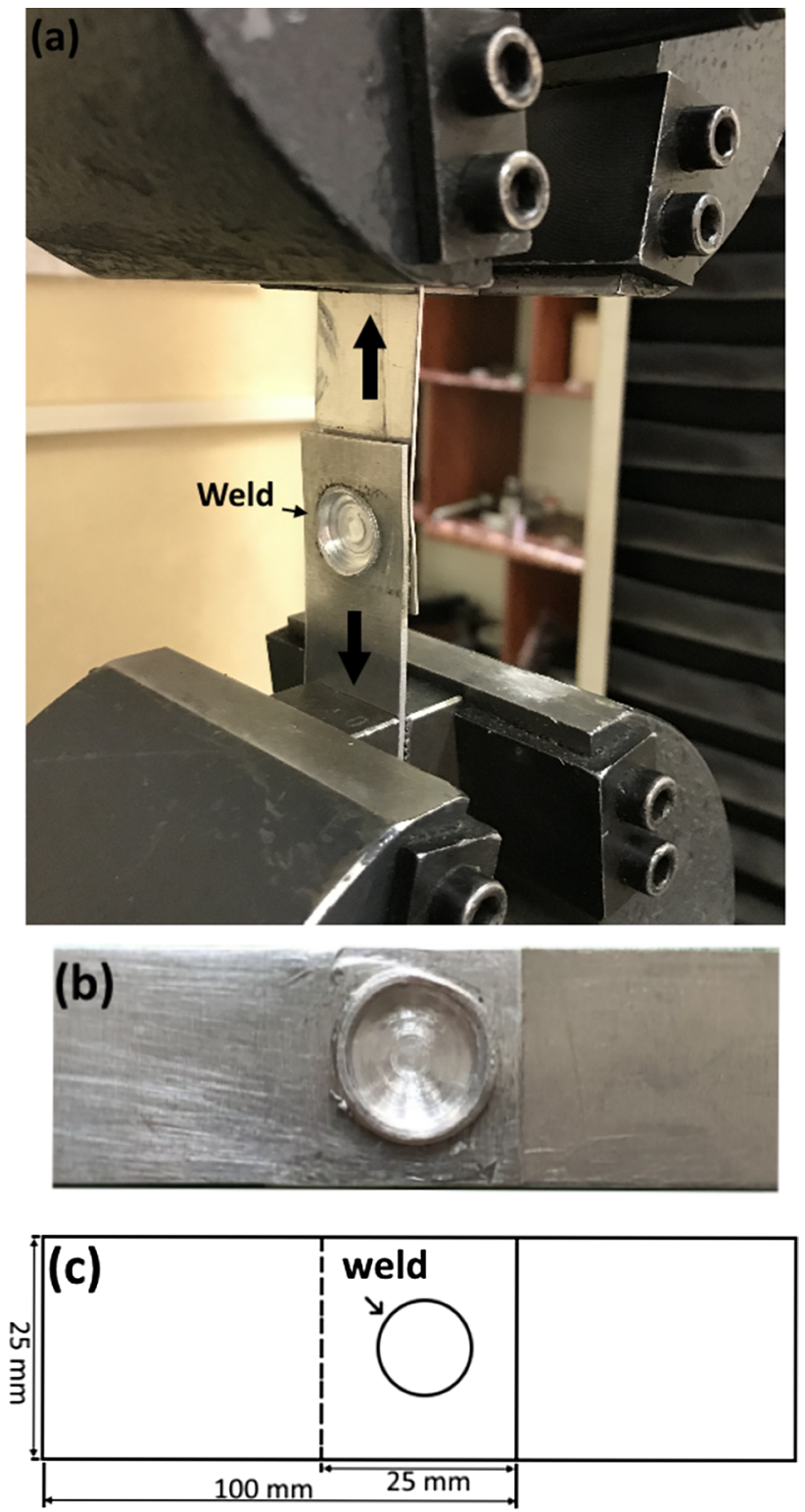

Fig. 2 Tensile test (a), b specimen and $\mathbf{c}$ dimensional procedure

on top surface. The severe deformation of material can be seen from bottom surface where softened material was extruded from the top workpiece material. Some amount of softens materials also flows towards the outer surface of tool shoulder (i.e. on the top surface of the workpiece) that in turn lead to flash formation. Bottom surface inspection can ensure the material extrusion fully in the predrilled cavity.

Figure 5 shows cross sectional macrograph of welded samples performed by smooth shoulder and scroll shoulder. It can be seen that the bulging between AA2024-T3 and AA6061-T6 was observed parallel to the shoulder diameter 
Fig. 3 Hardness measurement locations

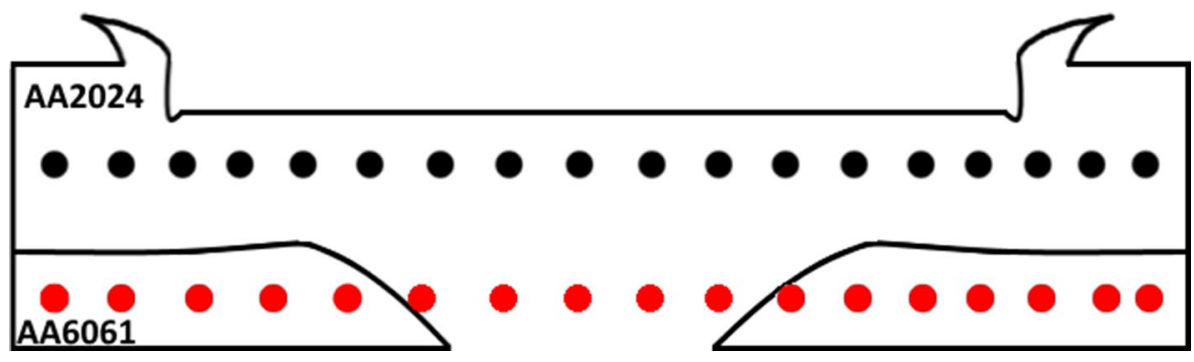

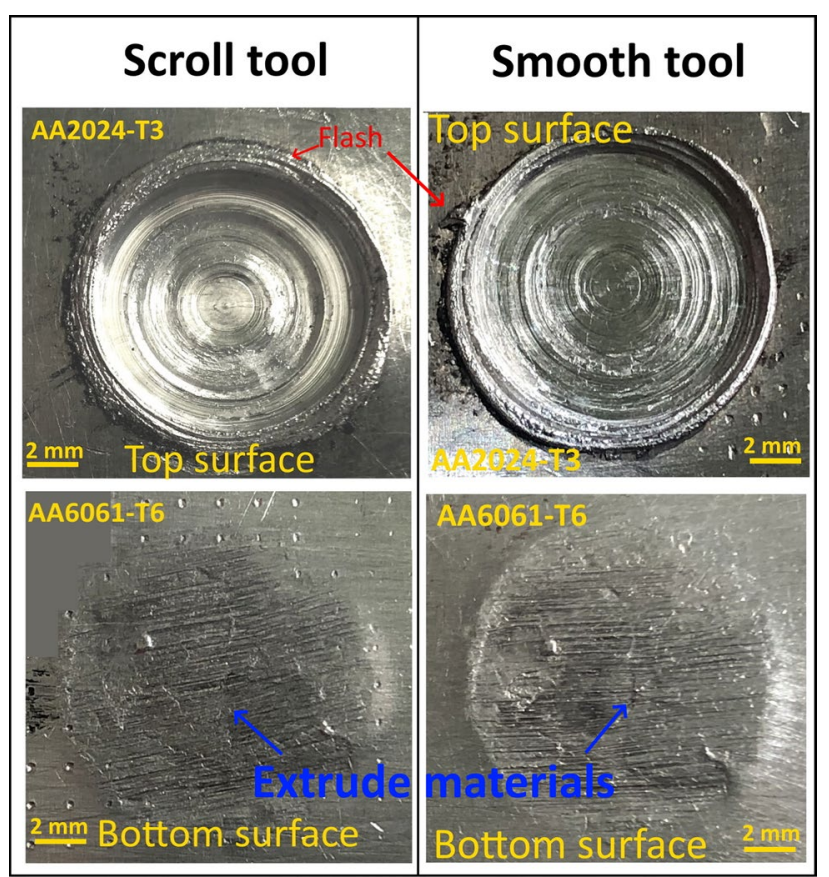

Fig. 4 Surface crown appearance after welding

surfaces. Besides, the material extrusion was successfully performed that subsequently resulted in defect free macrostructure in both weld samples. Macroscopically distinct features can also be observed from Fig. 5. The plunging of shoulder lead to shoulder indentation effect on top surface of AA2024-T3 that was subjected to deformation. The same material of AA2024-T3 was influenced by stir zone (SZ) and annular stir zone (ASZ) that were also influenced by shoulder features and consequently resulted different with scroll and smooth features. Both of these zones (i.e. SZ and ASZ) were observed wider in case of weld made by scroll shoulder features compare to the ones that were produced by smooth shoulder features. In case of smooth surface shoulder, the forging action was dominant that resulted in grater downward movement of material whereas dominant stirring-swirling action was responsible for material movement and mixing in horizontal as well as vertical direction that subsequently resulted in wider stir zone. Besides, the extruded material is filled towards the bottom workpiece (i.e. AA6061-T6) in the predrilled cavity that resulted in extruded zone also known as plastically deformed metal flow zone (PDZ). No major macroscopic variations were observed in the PDZ for the welds produced by scroll and smooth shoulder samples. Formation of thermo-mechanically affected zone (TMAZ) and heat affected zone (HAZ) were not macroscopically distinct but also expected to view in microscopic analysis as the same were reported in previous literature of probeless tool FSSW such as Bakavos et al. [12] and Klobčar et al. [24]. Additionally, Saju and Narayanan [3] observed similar variations of different zones in their macrograph results for friction extrusion joining. The formation of HAZ and TMAZ is confirmed by microscopic analysis in subsequent section.

\subsection{Microstructures and materials flow}

Figure 6 depicts microstructure of base materials of AA2024-T3 and AA6061-T6. It can be seen that the grains are elongated in the direction of rolling. This confirms processing of rolling (as received from vendor) before welding. Comparatively larger elongated grains can be observed in case of AA6061-T6 relative to AA2024-T3. However, both of these base materials can be characterized as coarse grain structure. Small spots of precipitates can also be observed in both of the images that are generally found as $\mathrm{CuAl}_{2}$, $\mathrm{CuAl}_{2} \mathrm{Mg}$ (for AA2024) and $\mathrm{Mg}_{2} \mathrm{Si}$ (for AA6061) as confirmed by SEM and EDX analysis shown in Fig. 7, which was also mentioned in literature of Moradi et al. [25], Haiyan and Mehta [26] and Gao et al. [27].

Microstructural features of friction spot extruded joints made by flat/smooth and scroll shoulder featured tools are shown in Figs. 8 and 9 respectively. SZ, ASZ, PDZ, and TMAZ can be distinctly seen from Figs. 8 and 9. Two 
Fig. 5 Macrographs of cross section a smooth tool, b scroll tool

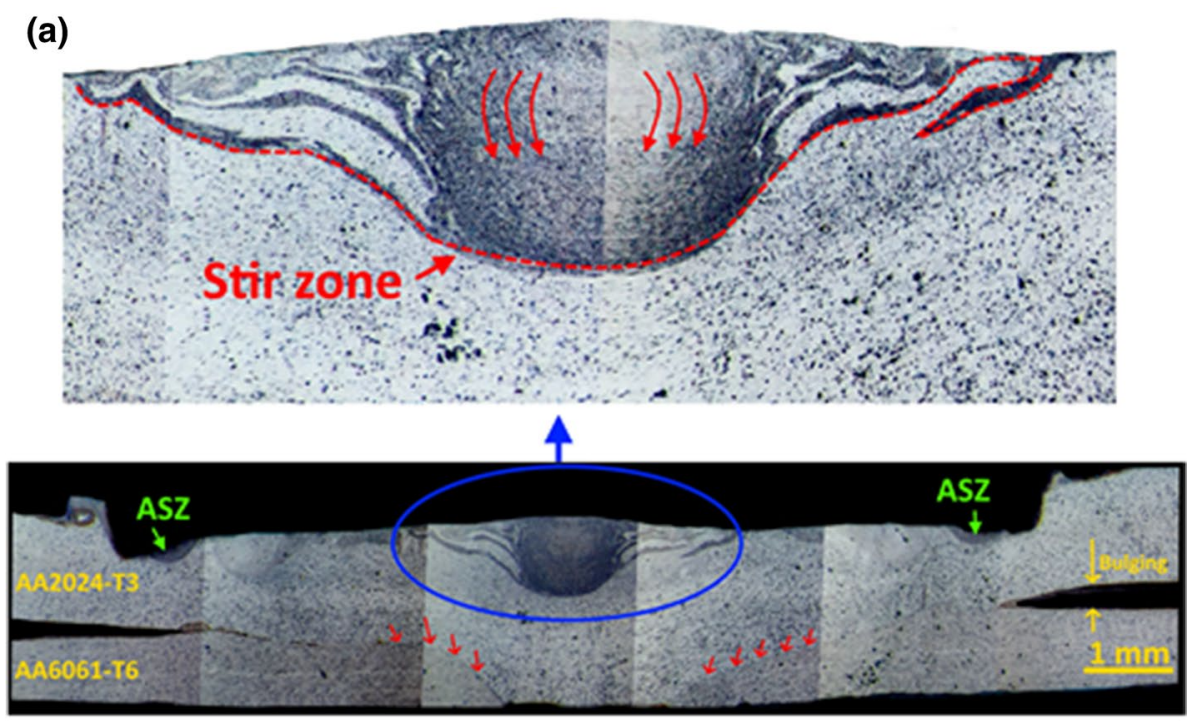

(b)
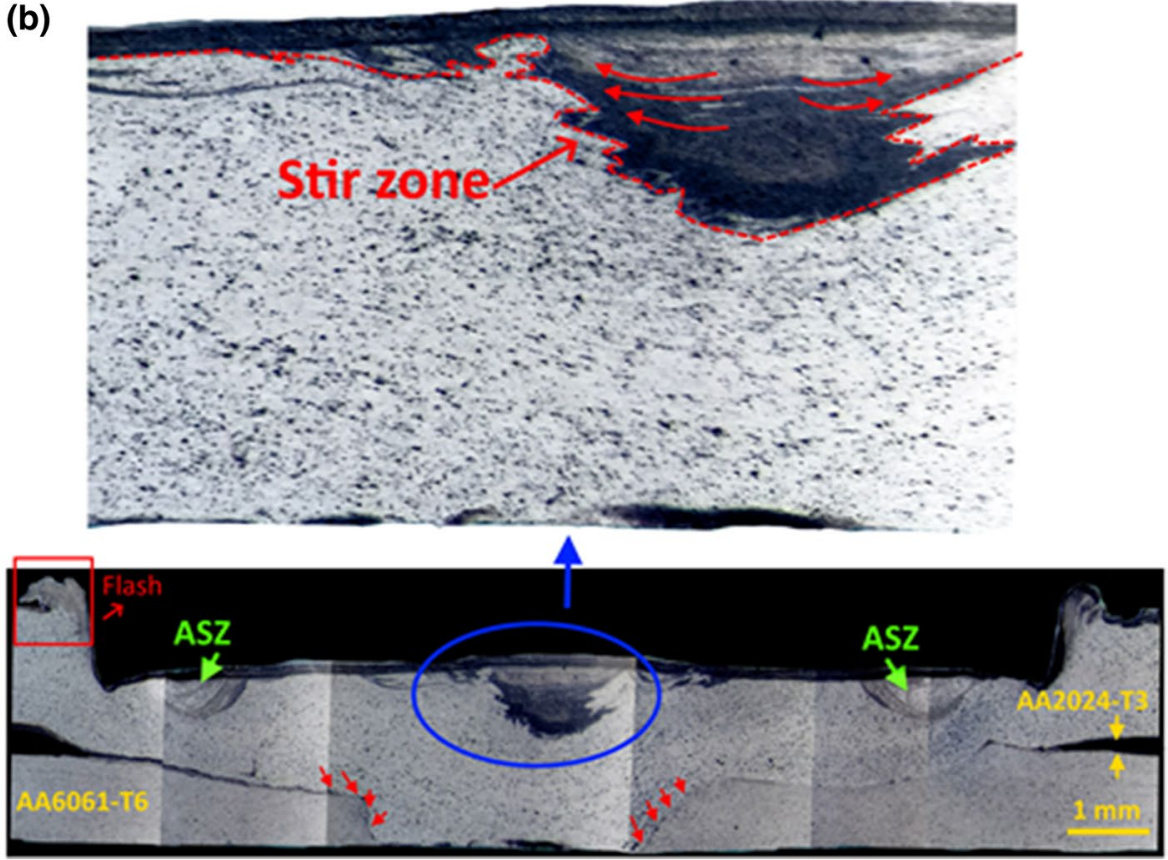

different materials flow caused by stirring and extrusion can be evidenced below the shoulder indentation in both of the welds. Grain refinement in the SZ can be seen (from Figs. 8d, e and 9b, d) with fine grins due to intense stirring deformation actions in the upper workpiece of AA2024-T3. However, the stirring actions were different due to differences in shoulder surface features. Large layers of stirring marks were observed in case of weld made by scroll shoulder (see Fig. 9d) due to swirling effect caused by scroll profile, whereas stirring layers without swirling marks were noted in case of weld made by smooth surface profile of tool.

Besides, no major differences in PDZ were observed with different shoulder features. PDZ is extruded recrystallized zone influenced by large forging action and low stirring action. Therefore, the grains of PDZ were elongated and large compare to stir zone.

The grains near to the interface between extruded zone and base material were elongated in the direction of forging, 
Fig. 6 Microstructure of base alloys, a AA2024-T3 and b AA6061-T6
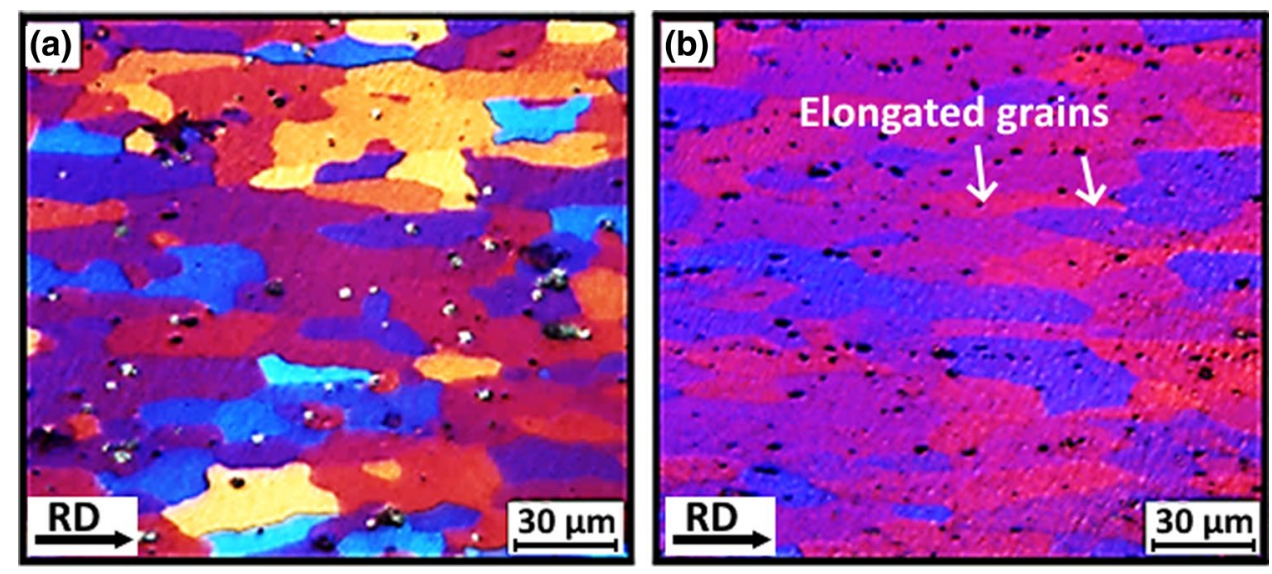
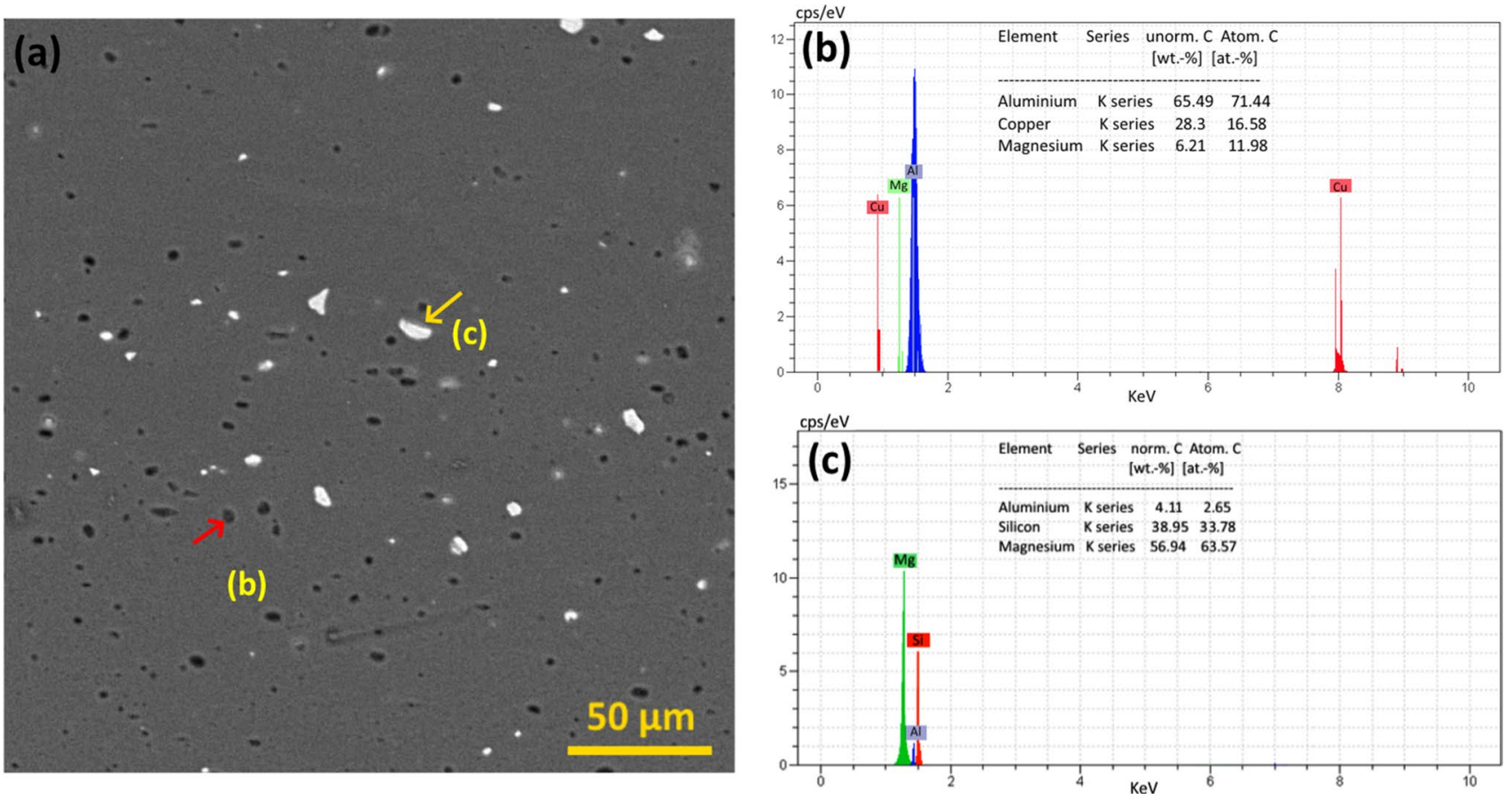

Fig. 7 SEM-EDX analysis on base materials a SEM image and $\mathbf{b}$ and $\mathbf{c}$ EDX results of indicated spots

whereas grains in the middle and below the $\mathrm{SZ}$ region were elongated with bowl shape due to influence of forging and stirring action. The boundary between extruded region and base material can be seen from Figs. $8 \mathrm{~b}$, c and $9 \mathrm{~b}, \mathrm{f}$, wherein the microstructural distinction can also be observed. Severe deformation of AA2024-T3 resulted with recrystallized grains at these interfaces, whereas the interaction surfaces of AA6061-T6 were influenced by diffusion that in turn resulted in joining along with mechanical locking of extruded material in the predrilled cavity. Beyond this, no complex intermixing of materials was observed in both cases.

Comparison on microstructural features in the zones of SZ and PDZ are shown in Fig. 10. It can be seen that finer grains were observed with $\mathrm{SZ}$ of smooth shoulder surface (Fig. 10a) compare to the same of scroll shoulder (Fig. 10b). 
Fig. 8 Microstructural features of welds made by flat/smooth tool: a macrograph with locations, b annular stir zone, $\mathbf{c}$ interface of joining, $\mathbf{d}$ stir zone-plastically deformed metal flow zone, e stirring features, $\mathbf{f}$ stir zone-thermo mechanically affected zone and $\mathbf{g}$ annular stir zone-thermo mechanically affected zone
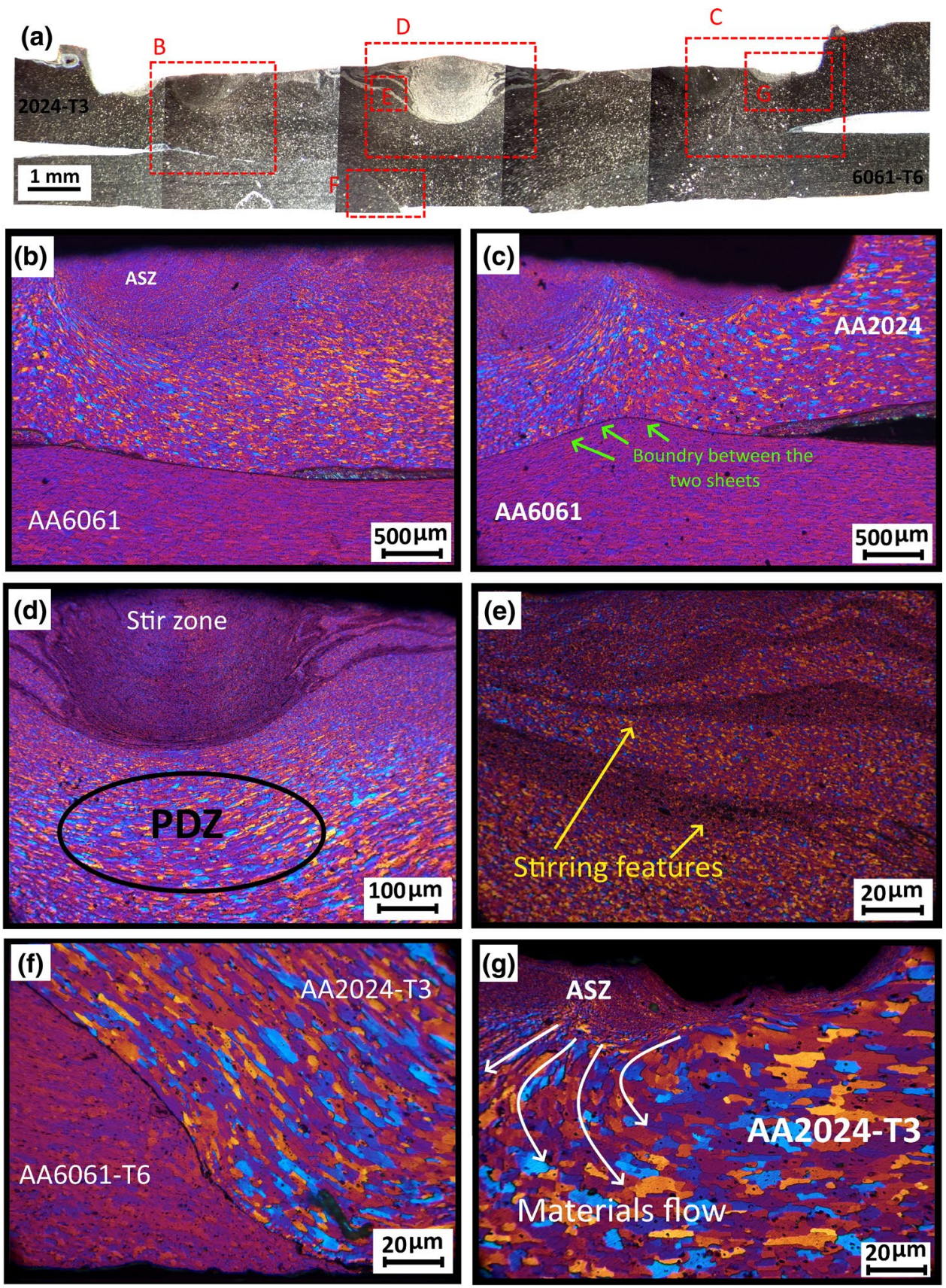

The proposed reason for these results were may be due to stirring layers differences caused by respective features. The scroll shoulder provided large layers of plastically deformed material with horizontal swirls, whereas the smooth shoulder features were resulted in stirring without large layered swirling. This in turn resulted with different grain structures.
Besides, the PDZ were also different for shoulder surface features. Elongated grains with clear extrusion layers can be seen in Fig. 10d, whereas no such layers were observed in the PDZ of smooth surface shoulder (Fig. 10c). This is again due to scroll features resulted in layered stirring. 
Fig. 9 Microstructural features of welds made by scroll tool: a macrograph with locations, $\mathbf{b}$ stir zone-plastically deformed metal flow zone, $\mathbf{c}$ annular stir zone-thermo mechanically affected zone interface of joining, $\mathbf{d}$ stirring features, e plastically deformed metal flow zone, f plastically deformed metal flow zone-AA6061-T6 interface and $\mathbf{g}$ annular stir zone
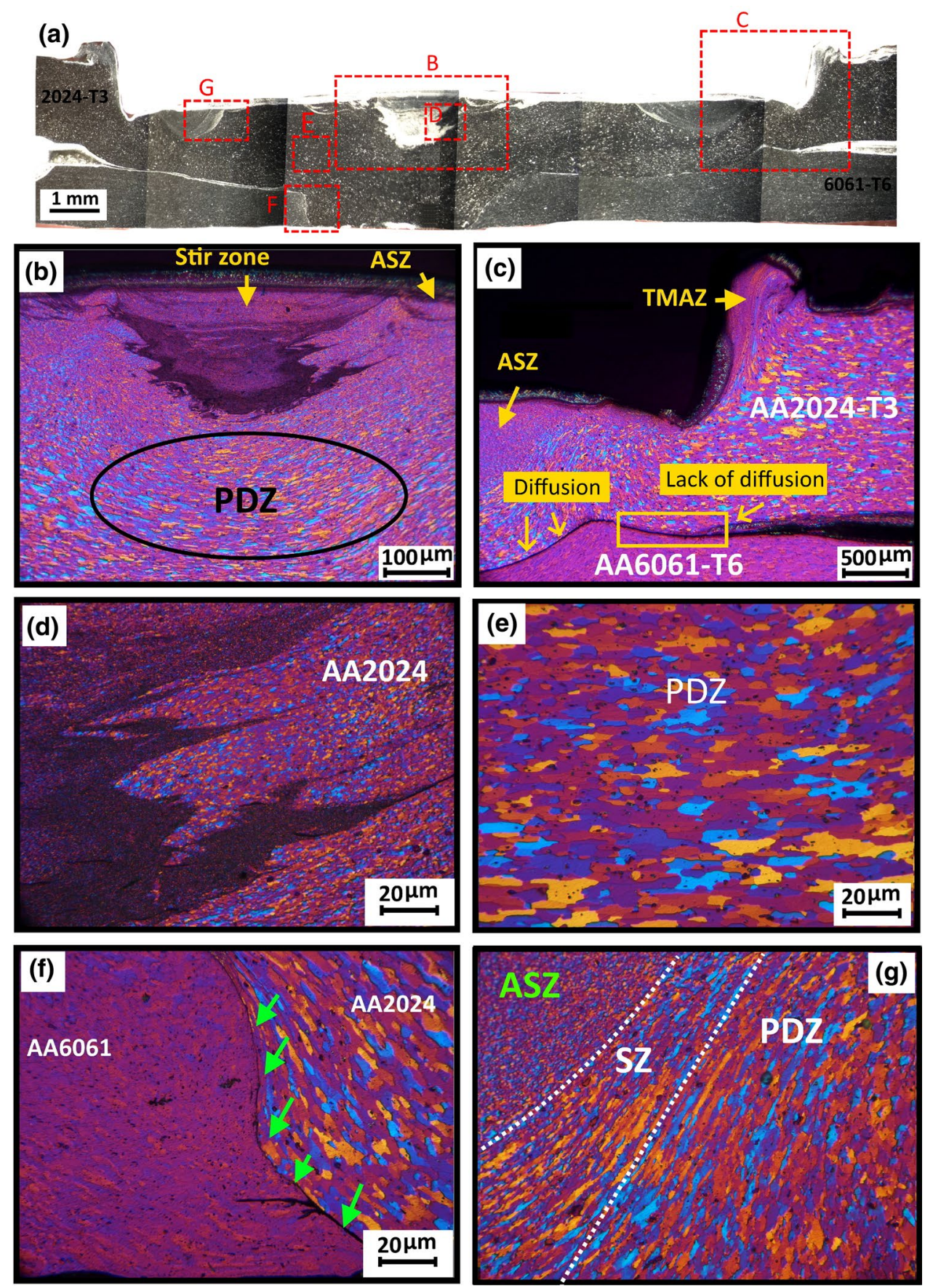

Aforementioned results and discussions of microstructural features can be correlated with results of EBSD as shown in Fig. 11. Relatively larger grain size was observed in scroll shoulder featured SZ, wherein majority of grains were directed like [101] as depicted from inverse pole figure
(IPF). Besides, in case of SZ of smooth shoulder, majority of the grains were directed in between [111] and [001] in addition to [101], as depicted from IPF. The direction of these crystal structure is different due to differences in surface profile features that can also be correlated with aforementioned 


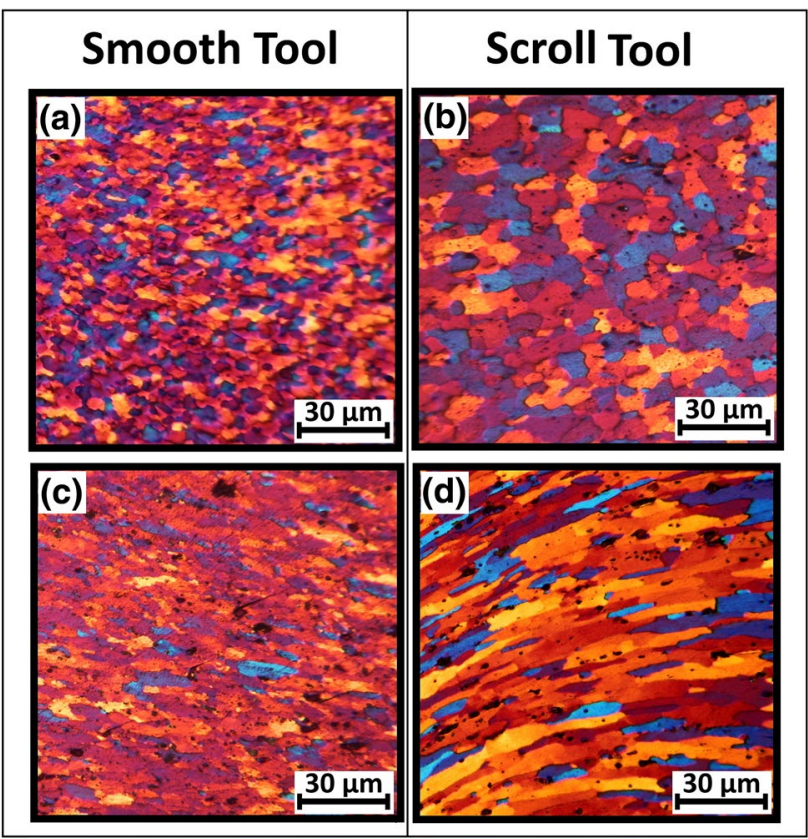

Fig. 10 Comparison of various microstructures as a function of tool feature a, b SZ, c, d PDZ
Figs. 8, 9, and 10. In case of PDZ, elongated grains can be again confirmed for both the cases of smooth shoulder feature and scroll shoulder features, as depicted from Fig. 11e and f, respectively. Furthermore, the HAZ was found with coarse round and elongated shaped grains.

The $\mathrm{SZ}$ region is further compared with TEM images as shown in Fig. 12. It can be seen that the precipitates were observed in both the cases but less in smooth shoulder SZ that may be due to some of them were dissolved during processing. Presence of precipitates can be predicted as $\mathrm{CuAl}_{2}$, $\mathrm{CuAl}_{2} \mathrm{Mg}$ as the $\mathrm{SZ}$ was mainly developed in the top material (i.e. AA2024), which was also mentioned in literature of Moradi et al. [25]. However, high density dislocations were observed in the SZ of smooth shoulder profile near to the grain boundary, which was not observed in case of SZ of scroll shoulder profile.

Materials stirring and bonding between AA2024-T5 and AA6061-T6 were evidenced by SEM images as shown in Fig. 13. It can be seen that the pores were observed in the stirring region in both the cases (Fig. 13a-d). But, larger pores were noticed in case of SZ of smooth shoulder (see Fig. 13a), wherein stirring layers were also observed (see Fig. 13b). Stirring was not so intense in case of smooth shoulder that may be the reason for these pores' formation. In case of SZ of scroll shoulder, more intense stirring layers were evidenced with very less amount of pores but

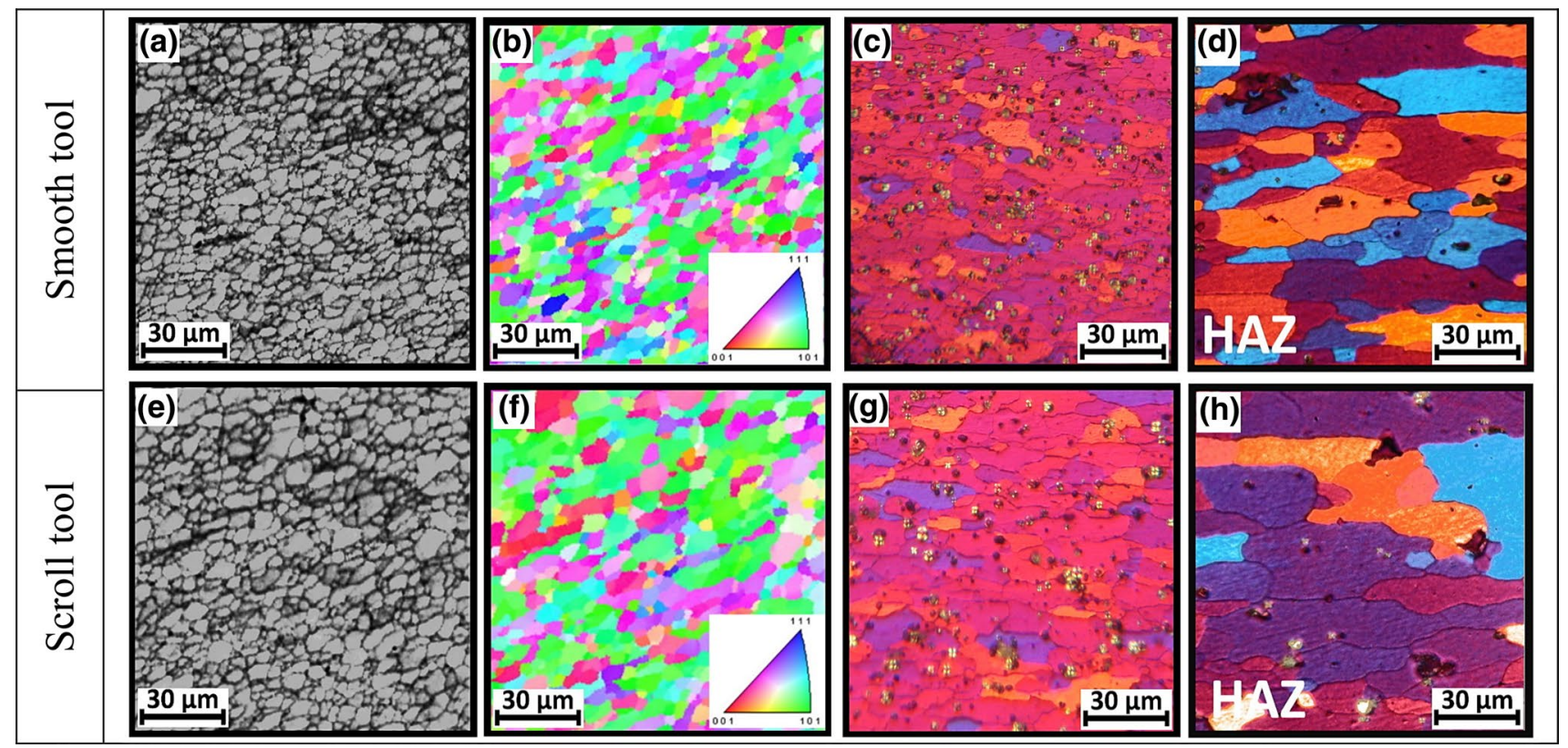

Fig. 11 IPF EBSD maps and micro grain structures as a function of tool features (a), (b) and (c), (d) SZ, (e) and (f) PDZ, and (g) and (h) HAZ 
Fig. 12 TEM images in the SZ, a smooth tool, b scroll tool
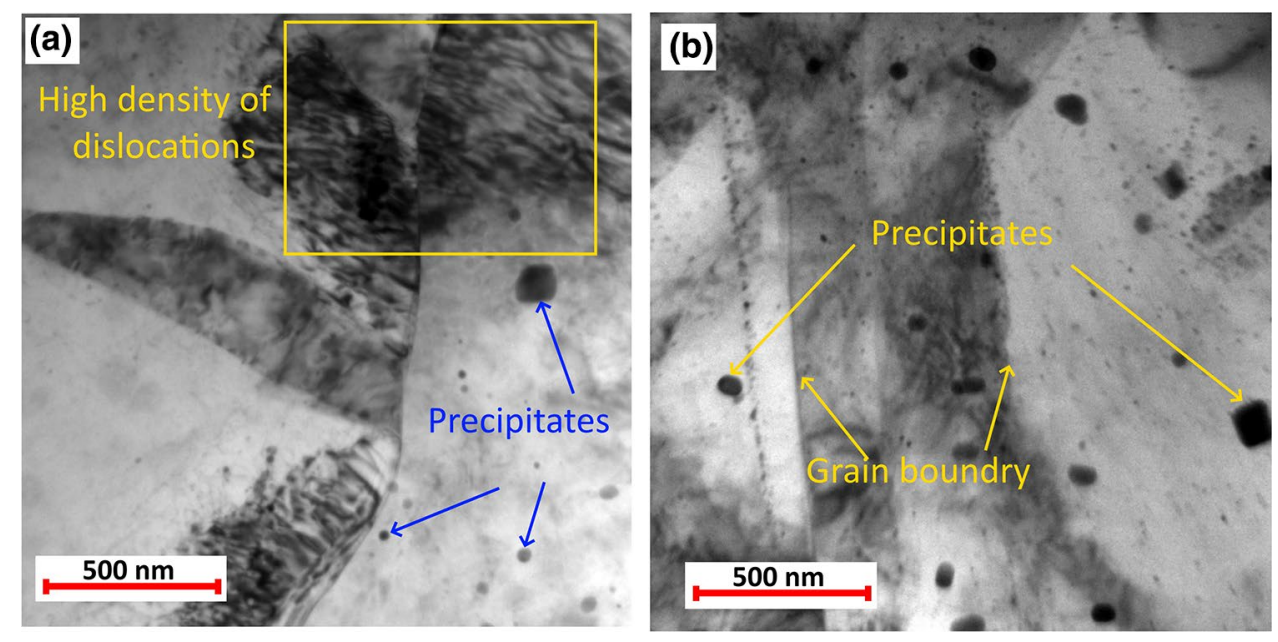

large amount of precipitates (see Fig. 13c, d) as compared to the same zone of smooth shoulder. On the other hand, the extruded zone interface between AA2024 and AA6061 was closely investigated with SEM as shown in Fig. 13e. The diffusion bonding can be evidenced from the image shown in Fig. 13 (e). In the extrusion zone, the formation of precipitates was evidenced in Fig. 13f that is in line with aforementioned discussion of precipitates in SZ and PDZ.

The materials mixing in PDZ interface with AA6061T6 material and outside of that interface towards the bulging side are shown in Fig. 14. Distinction of materials of AA2024-T5 and AA6061-T6 can be observed in Fig. 14a, however this mixing was found without any defect and can be reported as excellent with intermixing features caused by solid state diffusion between largely deformed AA2024T5 with partially deformed AA6061-T6. On the other hand, location outside of extrusion zone (refer location of Fig. 9c highlighted by lack of diffusion and diffusion), the bonding was found as partial as can be seen from Fig. 14b due to lack of diffusion phenomenon at this region. This was also may be due to heavily deformed material extruded in the cavity of predrilled location. The interface of AA2024-T5 and AA6061-T6 was also analyzed by SEM-EDX interpretation (refer Fig. 14c), wherein the formation of precipitates can be likely known based on the elemental results. Aforementioned precipitates of $\mathrm{Mg}_{2} \mathrm{Si}$ can be predicted based on area EDX performed as shown in Fig. 14c.

\subsection{Mechanical properties}

The tensile testing results of welds made by smooth shoulder and scroll shoulder are shown in Fig. 15 with load-extension curve. It can be seen that the tensile specimen of scroll shoulder was resulted to higher fracture load of $6381 \mathrm{~N}$, whereas the same was $4916 \mathrm{~N}$ in case of smooth shoulder, with minor difference in extension length. Better material mixing in SZ and PDZ in case of scroll shoulder weld as evidenced in previous section is responsible reason for higher fracture load compared to smooth shoulder welds. The tensile specimens were fractured from the interface between PDZ and base material of AA6061-T6 as can be seen from Fig. 16, and hence this zone can be considered as weakest zone in case of friction spot extrusion. Large flat surfaces and full grains were observed on SEM images that can be interpreted as trans-granular fracture. Small diffusion layer between PDZ and base material is weakest region with likely presence of aforementioned precipitates, which subsequently led to cause of this trans-granular fracture mode.

Hardness distribution across the welded cross section for the smooth shoulder surface and scroll surface are shown in Fig. 17a and b respectively. No major variations in the hardness between welds made by smooth and scroll shoulder features were reported. However, overall variations in Vickers hardness number were from 40 to $150 \mathrm{HV}$. The variations of SZ, PDZ and TMAZ were observed large compare to base material hardness. Saju and Narayanan [3] observed similar type of hardness variation features. In both of the cases of 
Fig. 13 Stirring layers and extrusion zone interface of $\mathbf{a}$, b smooth shoulder, c, $\mathbf{d}$ scroll shoulder, e bonding between AA2024 and AA6061 and f precipitates in extrusion zone
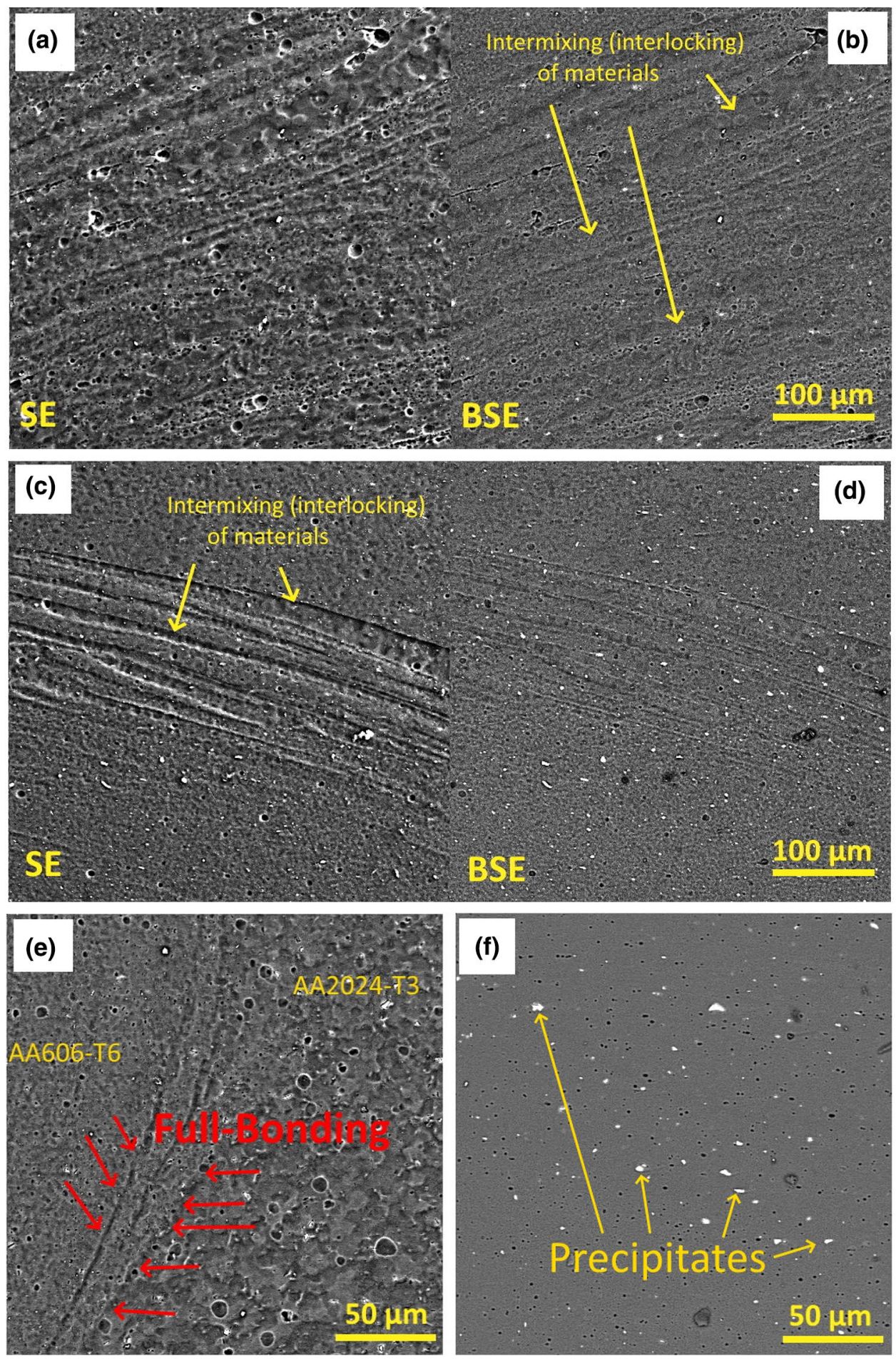

smooth shoulder and scroll shoulder, the maximum hardness peaks were observed in the PDZ. In this PDZ region, the hardness across the bottom workpiece (i.e. AA6061-T6) was found nearly equal to the hardness of AA2024-T3 material. This is due to extruded material of AA2024-T3 consisted in PDZ region. Furthermore, in scroll shoulder's weld, the hardness variations in top workpiece of AA2024-T3 can be found as large compare to rest of hardness distribution. Layered stirring-swirling effect resulted in comparatively coarse grain that subsequently resulted in decrease in hardness of SZ. 


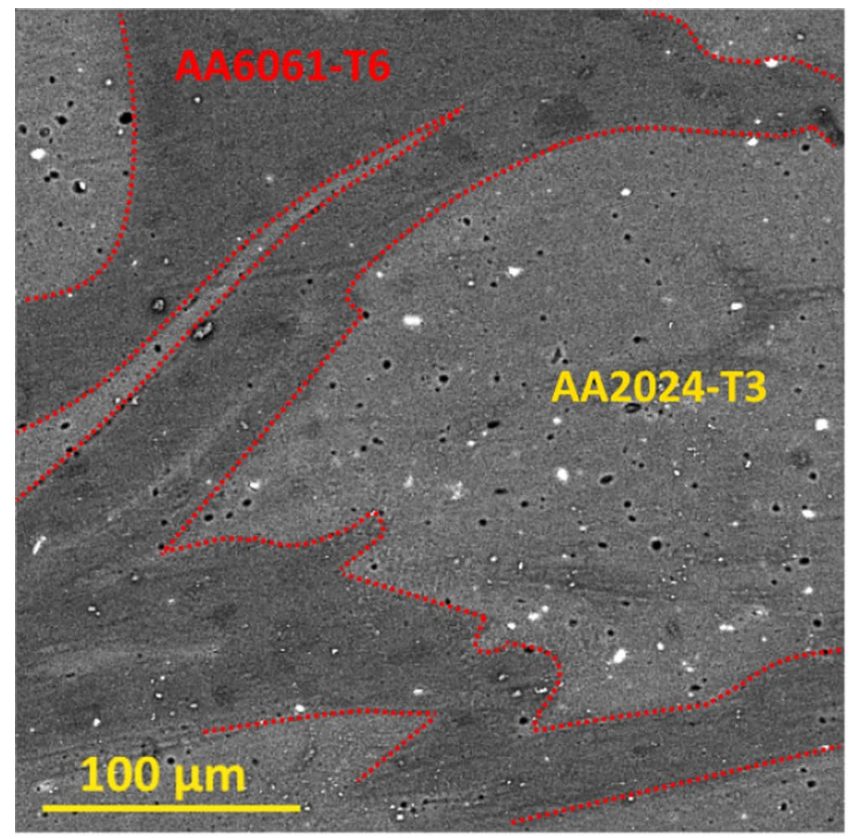

(a)
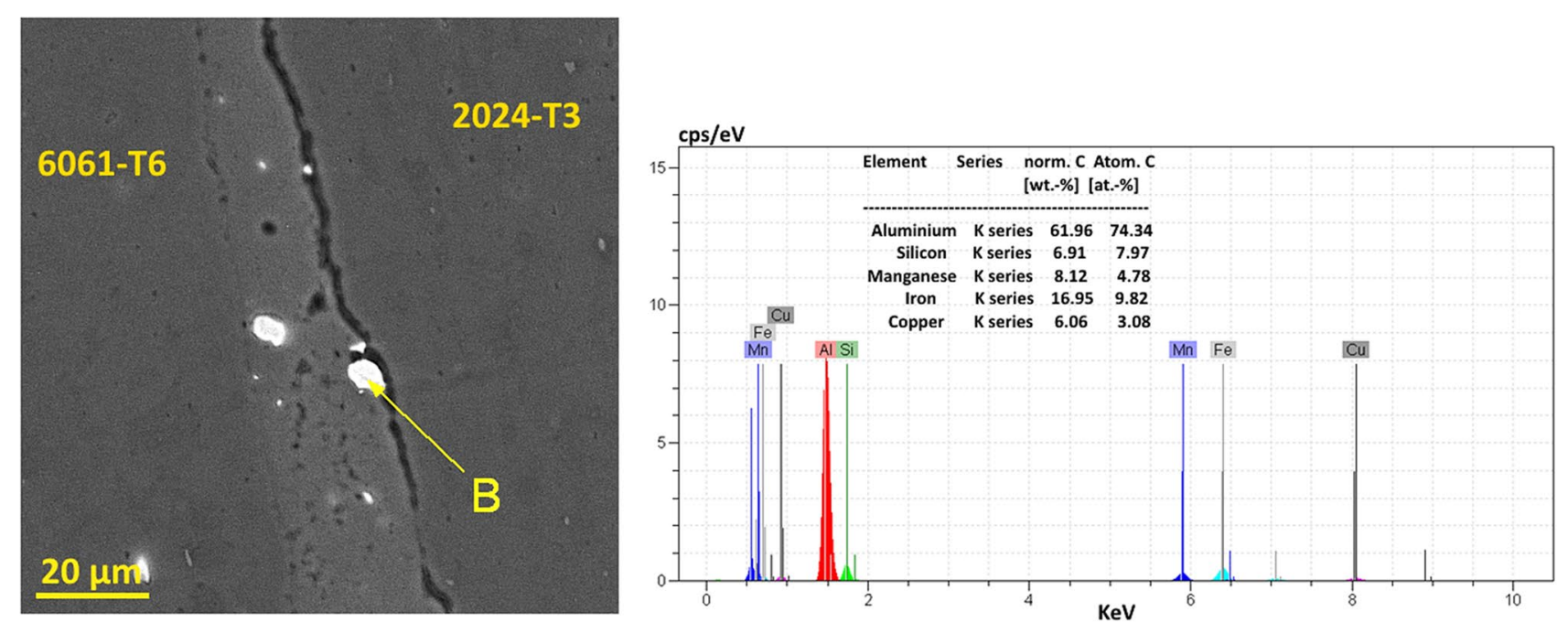

(c)

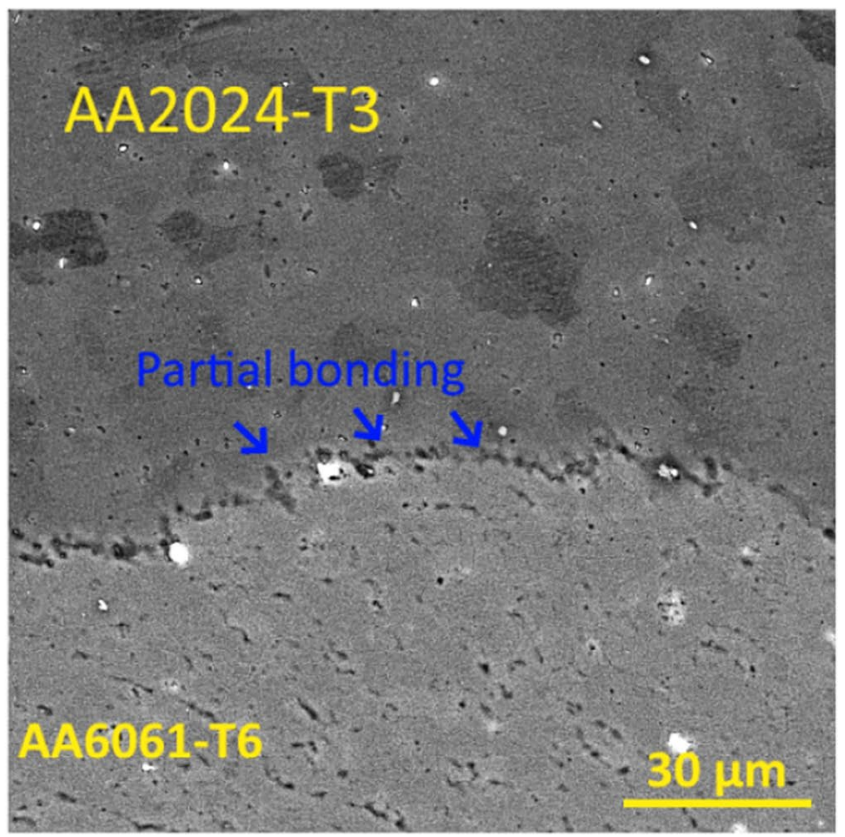

(b)

Fig. 14 a Excellent bonding features, $\mathbf{b}$ partial bonding region and $\mathbf{c}$ elements information by SEM-EDX area analysis

\section{Conclusions}

Friction spot extrusion welding process was successfully performed on dissimilar aluminum alloys of AA2024-T3 and AA6061-T6. The effect of shoulder features such as scroll shoulder and smooth shoulder was analysed with the objective of investigating microstructure and mechanical properties of the spot welds. From the investigation, following conclusions can be presented.

1. The joining in friction spot extrusion welding was obtained by combination of mechanical locking from extruded material of top surface to predrilled bottom surface and diffusion in solid state. 
Fig. 15 Load-extension curve for tensile testing

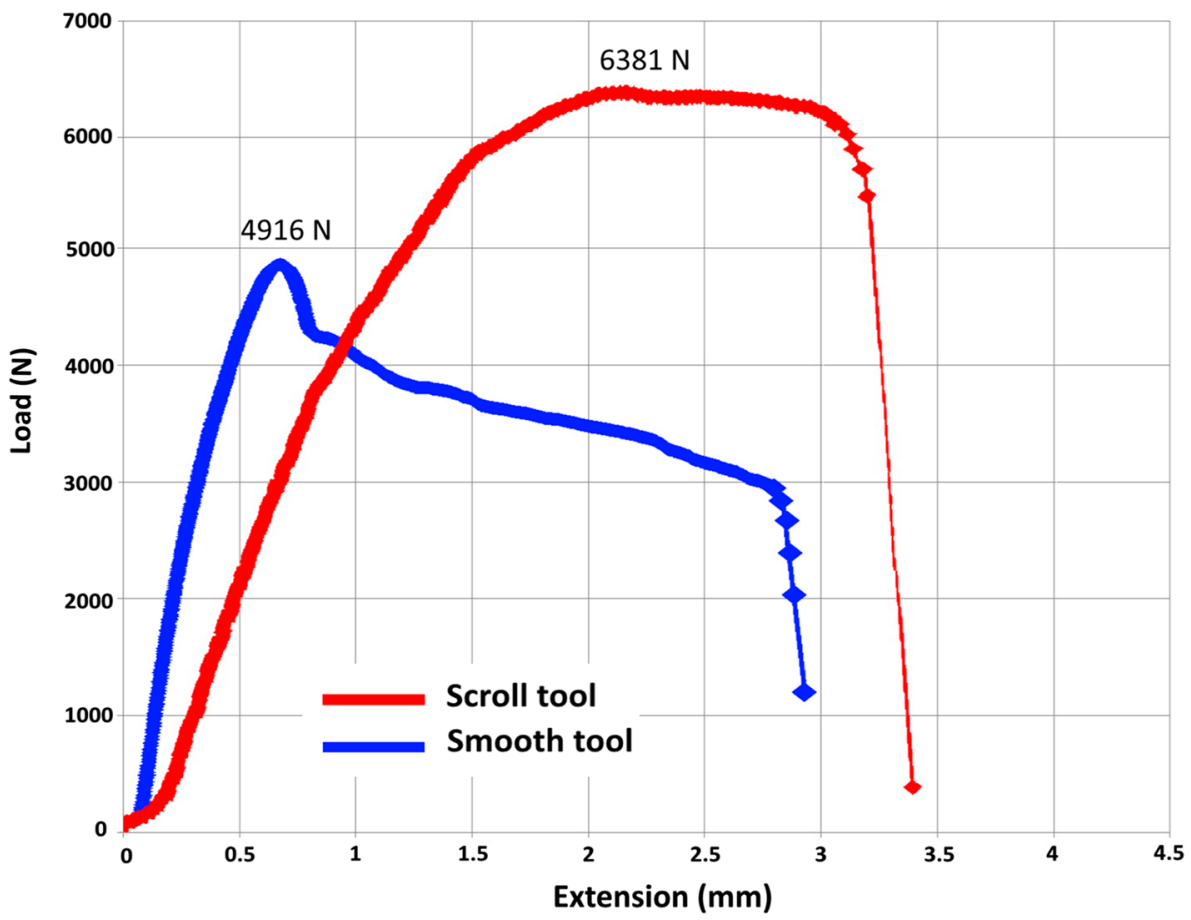

2. The stir zone and plastically deformed metal flow zone were influenced by scroll shoulder and smooth shoulder features. Wider stir zone was observed with large layers of stirring-swirling marks in case of weld made by scroll shoulder.

3. Larger grain size was observed in scroll shoulder featured stir zone, wherein majority of grains were directed like [101]. Besides, in case of stir zone of smooth shoulder, majority of the grains were directed in between [111] and [001] in addition to [101].

4. The tensile specimen of scroll shoulder was resulted to higher fracture load of $6381 \mathrm{~N}$ whereas the same was $4916 \mathrm{~N}$ in case of smooth shoulder. The tensile specimens were fractured from the interface between plastically deformed metal flow zone and base material of AA6061-T6. The interface of between plastically deformed metal flow zone and base material of AA6061T6 can be considered as critical/weakest zone in case of friction spot extrusion.

5. The variations of hardness were observed in stir zone, plastically deformed metal flow zone and thermomechanically affected zone in case of friction spot extrusion welding process. The variations in Vickers hardness number were from 40 to $150 \mathrm{HV}$. 
Fig. 16 Fracture surface features after tensile testing (scroll shoulder welded specimen)
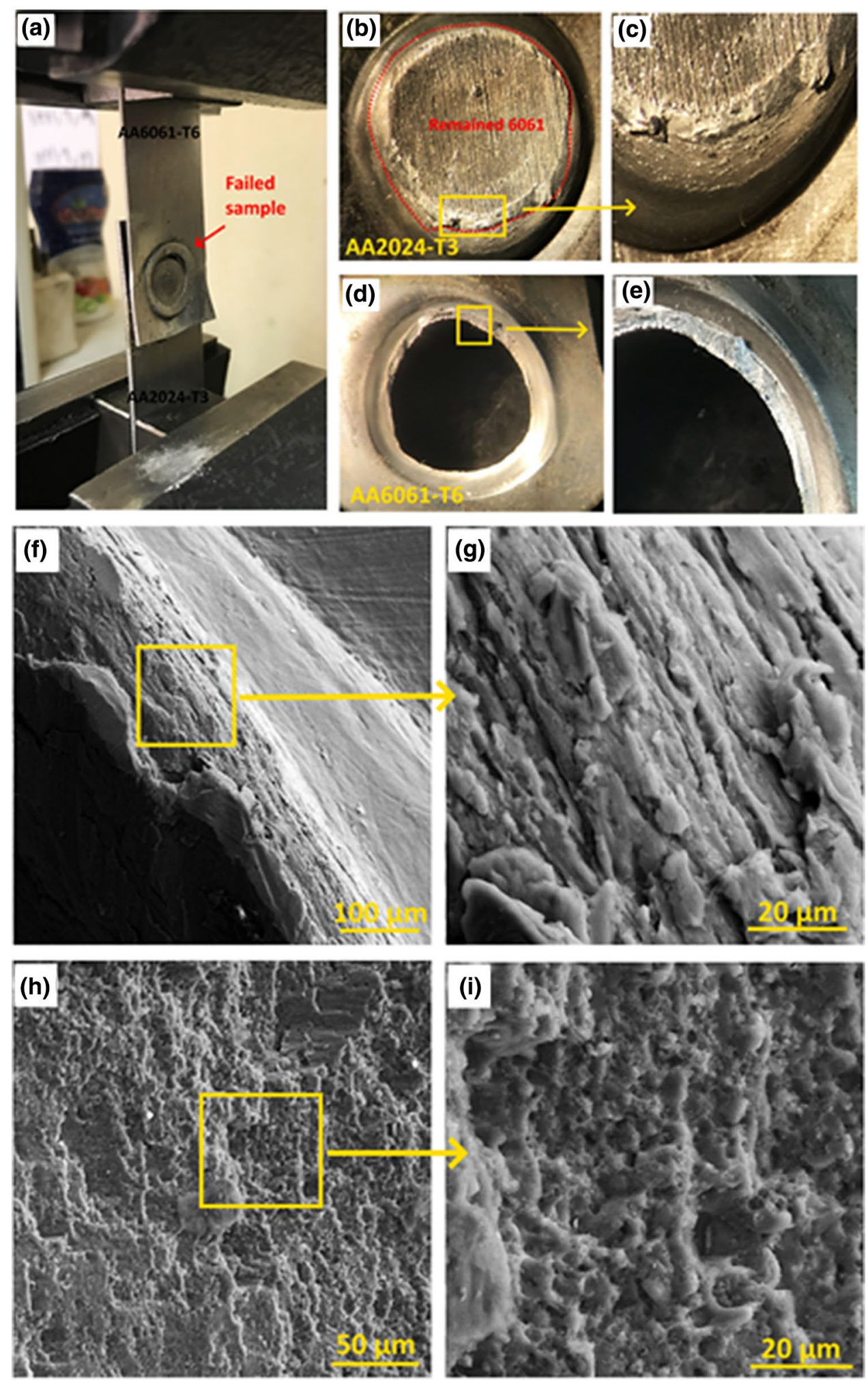

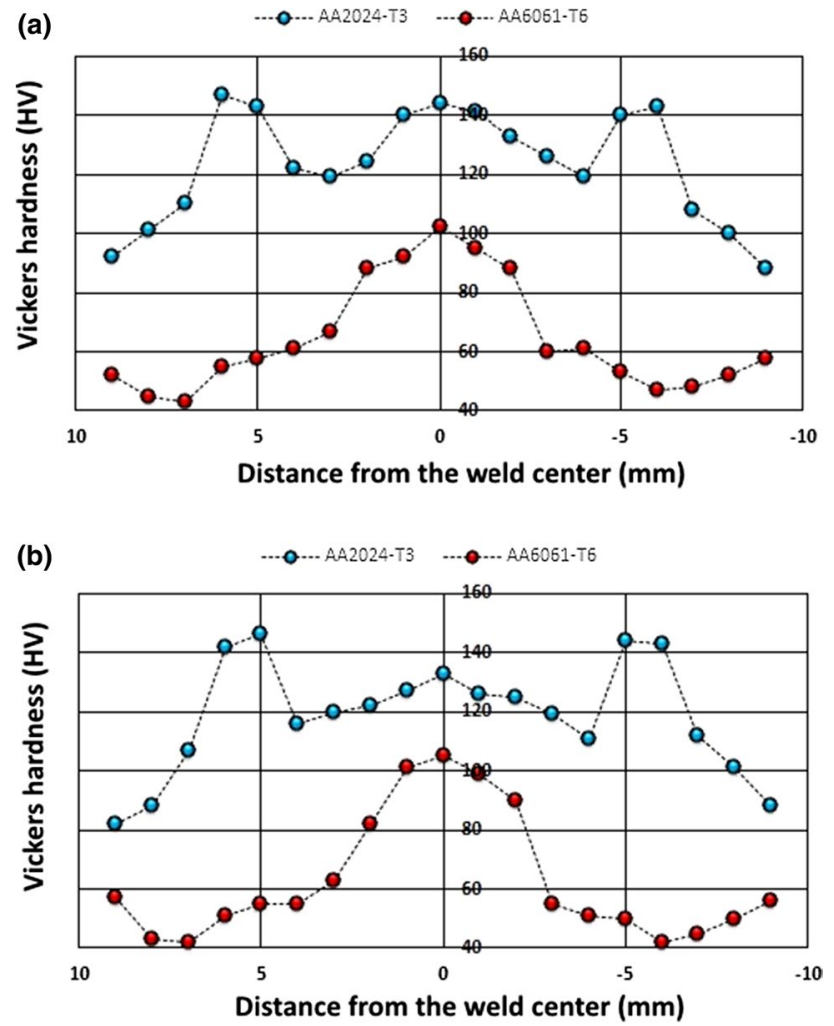

Fig. 17 Hardness measurement lines for welds of a smooth tool, and b scroll tool

Acknowledgments Open access funding provided by Aalto University.

Funding Funded by the Education Department of Zhejiang Province (Y201737845); Shaoxing Education Science Planning Project in 2020 (SGJ2048).

\section{Compliance with ethical standards}

Conflict of interest The authors declare that they have no conflict of interest.

Ethics approval We confirm that this work is original and has not been published elsewhere, nor it is currently under consideration for publication elsewhere. All authors have approved the manuscript and have agreed with its submission to your journal.

Open Access This article is licensed under a Creative Commons Attribution 4.0 International License, which permits use, sharing, adaptation, distribution and reproduction in any medium or format, as long as you give appropriate credit to the original author(s) and the source, provide a link to the Creative Commons licence, and indicate if changes were made. The images or other third party material in this article are included in the article's Creative Commons licence, unless indicated otherwise in a credit line to the material. If material is not included in the article's Creative Commons licence and your intended use is not permitted by statutory regulation or exceeds the permitted use, you will need to obtain permission directly from the copyright holder. To view a copy of this licence, visit http://creativecommons.org/licenses/by/4.0/.

\section{References}

1. Ojo OO, Taban E, Kaluc E. Friction stir spot welding of aluminum alloys: a recent review. Mater Test. 2015;57:609-27.

2. Mehta KP. A review on friction-based joining of dissimilar aluminum-steel joints. J Mater Res. 2019;34:78-96. https://doi. org/10.1557/jmr.2018.332.

3. Saju TP, Narayanan RG. Dieless friction stir extrusion joining of aluminum alloy sheets with a pinless stir tool by controlling tool plunge depth. J Mater Process Technol. 2020;276:116416.

4. Lin PC, Lo SM. Friction stir clinching of alclad AA2024-T3 sheets. Int J Adv Manuf Technol. 2017;92:2425-37. https://doi. org/10.1007/s00170-017-0337-7.

5. Uematsu Y, Tokaji K. Comparison of fatigue behaviour between resistance spot and friction stir spot welded aluminium alloy sheets. Sci Technol Weld Join. 2009;14:62-71.

6. Mehta KP, Patel R. On fsw keyhole removal to improve volume defect using pin less tool. Key Eng. Mater. 2019;821:215-21.

7. Huang YX, Han B, Tian Y, Liu HJ, Lv SX, Feng JC, Leng JS, Li Y. New technique of filling friction stir welding. Sci Technol Weld Join. 2011;16:497-501.

8. Behmand SA, Mirsalehi SE, Omidvar H, Safarkhanian MA. Filling exit holes of friction stir welding lap joints using consumable pin tools. Sci Technol Weld Join. 2015;20:330-6.

9. Reimann M, Gartner T, Suhuddin U, Göbel J, Dos Santos JF. Keyhole closure using friction spot welding in aluminum alloy 6061-T6. J Mater Process Technol. 2016;237:12-8. https://doi. org/10.1016/j.jmatprotec.2016.05.013.

10. Chen K, Liu X, Ni J. Keyhole refilled friction stir spot welding of aluminum alloy to advanced high strength steel. J Mater Process Technol. 2017;249:452-62. https://doi.org/10.1016/j.jmatprotec .2017.06.039.

11. Shen Z, Li WY, Ding Y, Hou W, Liu XC, Guo W, Chen HY, Liu $X$, Yang J, Gerlich AP. Material flow during refill friction stir spot welded dissimilar Al alloys using a grooved tool. J Manuf Process. 2020;49:260-70.

12. Bakavos D, Chen Y, Babout L, Prangnell P. Material interactions in a novel pinless tool approach to friction stir spot welding thin aluminum sheet. Metall Mater Trans A Phys Metall Mater Sci. 2011;42:1266-82.

13. Paidar M, Ghavamian S, Ojo OO, Khorram A, Shahbaz A. Modified friction stir clinching of dissimilar AA2024-T3 to AA7075T6: effect of tool rotational speed and penetration depth. J Manuf Process. 2019;47:157-71.

14. Paidar M, Ojo OO, Moghanian A, Karapuzha AS, Heidarzadeh A. Modified friction stir clinching with protuberance-keyhole levelling: a process for production of welds with high strength. J Manuf Process. 2019;41:177-87.

15. Paidar M, Vignesh RV, Khorram A, Ojo OO, Rasoulpouraghdam A, Pustokhina I. Dissimilar modified friction stir clinching of AA2024-AA6061 aluminum alloys: effects of materials positioning. J Mater Res Technol. 2020;9(3):6037-47.

16. Paidar M, Vaira Vignesh R, Moharrami A, Ojo OO, Jafari A, Sadreddini $S$. Development and characterization of dissimilar joint between AA2024-T3 and AA6061-T6 by modified friction stir clinching process. Vacuum. 2020;176:109298.

17. Mehta KP, Patel R, Vyas H, Memon S, Vilaça P. Repairing of exit-hole in dissimilar $\mathrm{Al}-\mathrm{Mg}$ friction stir welding: process and microstructural pattern. Manuf Lett. 2020;23:67-70.

18. Lazarevic S, Ogata KA, Miller SF, Kruger GH, Carlson BE. Formation and structure of work material in the friction stir forming process. J Manuf Sci Eng Trans ASME. 2015;137:1-9.

19. Evans WT, Gibson BT, Reynolds JT, Strauss AM, Cook GE. Friction stir extrusion: a new process for joining dissimilar materials. Manuf Lett. 2015;5:25-8. 
20. Hussein SK, Abdullah IT, Hussein AK. Spot lap joining of AA5052 to AISI 1006 by aluminium extrusion via friction forming technique. Multidiscip Model Mater Struct. 2019;15:1337-511.

21. Jarrell AW, Cui J, Strauss AM, Cook GE. Friction stir extrusion of thin sheet stock. Lett Manuf. 2020. https://doi.org/10.1016/j. mfglet.2020.03.008.

22. Saju TP, Narayanan RG, Roy BS. Effect of pinless tool shoulder diameter on dieless friction stir extrusion joining of AA 5052-H32 and AA 6061-T6 aluminum alloy sheets. J Mech Sci Technol. 2019;33:3981-97.

23. Saju TP, Narayanan RG. Dieless friction stir lap joining of AA 5050-H32 with AA 6061-T6 at varying pre-drilled hole diameters. J Manuf Process. 2020;53:21-33.
24. Klobčar D, Tušek J, Smolej A, Simončič S. Parametric study of FSSWof aluminium alloy 5754 using a pinless tool. Weld World. 2015;59:269-81.

25. Moradi MM, Jamshidi Aval H, Jamaati R, Amirkhanlou S, Ji S. Microstructure and texture evolution of friction stir welded dissimilar aluminum alloys: AA2024 and AA6061. J Manuf Process. 2018;32:1-10

26. Haiyan Z, Mehta KP. Effect of materials positioning on dissimilar modified friction stir clinching between aluminum 5754-O and 2024-T3 sheets. Vacuum. 2020;178:109445.

27. Gao P, Zhang Y, Mehta KP. Metallurgical investigation of $\mathrm{Al}-\mathrm{Cu}$ joint by friction stir spot welding and modified friction stir clinching. Metals Mater Int. 2020. https://doi.org/10.1007/s12540-02000759-w (accepted). 